\title{
Factors Influencing Food Choices Among Older Adults in the Rural Western USA
}

\author{
Carmen Byker Shanks ${ }^{1} \cdot$ Sarah Haack $^{2} \cdot$ Dawn Tarabochia $^{3} \cdot$ Kate Bates $^{4} \cdot$ \\ Lori Christenson ${ }^{5}$
}

(C) Springer Science+Business Media New York 2016

\begin{abstract}
Nutrition is an essential component in promoting health and quality of life into the older adults years. The purpose of this qualitative research is to explore how the rural food environment influences food choices of older adults. Four focus groups were conducted with 33 older adults (50 years of age and older) residing in rural Montana communities. Four major themes related to factors influencing food choices among rural older adults emerged from this study: perception of the rural community environment, support as a means of increasing food access, personal access to food sources, and dietary factors. The findings from this current study warrant further research and promotion
\end{abstract}

Carmen Byker Shanks

cbykershanks@montana.edu

Sarah Haack

sarahhaack@gmail.com

Dawn Tarabochia

dawn.tarabochia@montana.edu

Kate Bates

katejolenebates@gmail.com

Lori Christenson

lori.christenson@gallatin.mt.gov

1 Food and Health Lab, Department of Health and Human Development, Montana State University, 960 Technology Boulevard, Room 215, Bozeman, MT 59718, USA

2 Censeo Consulting Group, Washington, DC, USA

3 Community Health, Montana State University, Bozeman, MT 59717-3540, USA

4 Dietetic Internship Program, Western Carolina University, Asheville, NC 28723, USA

5 Environmental Health, Gallatin City-County Health Department, Bozeman, MT 59715, USA of specifically tailored approaches that influence the food choices of older adults in the rural western USA, including the developing and expanding public transportation systems, increasing availability of local grocers with quality and affordable food options, increasing awareness and decreasing stigma surrounding community food programs, and increasing nutrition education targeting senior health issues.

Keywords Seniors · Nutrition · Food access ·

Eating behaviors

\section{Introduction}

Older adults are particularly vulnerable to nutrition-related risks such as malnutrition and chronic disease $[1,2]$. Nutrition, thus, is an essential component in promoting health and quality of life into the older adult years [3, 4]. During all stages of life, dietary intake is influenced by a multitude of factors that should be studied at the individual, social, and environmental levels $[5,6]$. For example, the relationship between older adult food insecurity and poor nutrition and health outcomes illustrates that food consumption is influenced by many factors including economics, social support, ethnicity, and gender [7-10].

In both urban and rural food environments, access to healthy food choice is generally influenced by availability (e.g., of nutritious foods), affordability (e.g., ability to pay food prices), accommodation (e.g., food outlet adaptation to consumer needs), accessibility (e.g., location of food outlet), and acceptability (e.g., food outlet meeting consumer preferences) [11]. Of recent interest is how characteristics of the rural environment - specifically geographic remoteness from food outlets, inadequate infastructure in communities, and limited food options-affect access to healthy food 
choices for target populations residing in those locations [12-14]. Distinct consequences in nutrition-related health behaviors, including lower fruit and vegetable consumption [15], are correlated with health outcomes, including higher obesity and chronic disease rates [16, 17], in rural areas.

There is a small but growing body of literature in the area of access to healthy foods for older adults in rural areas, with food security and its related consequences exacerbated by the rural environment. In one study, a relationship was established between food insecure rural Appalachian older adults and the likelihood of facing health, social, and material barriers; being low-income; being on prescription drugs; and eating alone [18]. Rural widows in North Carolina indicated negative nutrition-related behaviors, such as reduced home food production, in their diet [19]. Rural older adults in North Carolina were likely to participate in food sharing [20] and were not likely to meet dietary recommendations [21]. In rural Pennsylvania, the dietary patterns of older adults who were categorized with a low nutrientdense diet were twice as likely to be obese [22]. In Mississippi, rural older adults who were food insecure had lower quality dietary intake [23]. In rural New Mexico, older adults were likely to choose foods based on ease of preparation, availability of food sources, household resources, limited choices, health-related diet changes, and a diminished desire to eat [24]. In rural Texas, food insecurity in older adults was related to social capital, perceived personal disparity, and partnership status [7]. Older adult rural women living alone in the US were more likely to be overweight than rural US men with a high body mass index [25].

The purpose of this qualitative research is to add to the literature about older adult nutrition in rural areas and explore the factors that influence food choices of older adults living in rural communities of western USA from a food environment perspective.

\section{Methods}

\section{Data Collection}

The Institutional Review Board at Montana State University approved the research protocol. Rural communities were selected for inclusion by choosing locations with a senior center, within 50 miles of the researcher's town, and within non-metro counties based on a rating of $>3$ from the 2013 USDA rural-urban continuum code [26] database (RUCC). RUCC ratings range from 1 to 10 , with 1 to 3 being metro, and 4 to 10 being non-metro. Researchers coordinated with senior center directors to advertise each focus group for scheduled time and date through flyers and announcements. In addition, flyers were placed in food outlets throughout rural communities.
Two trained and experienced research assistants, whose roles were moderator and co-moderator, conducted the focus groups. Participants who attended the focus group completed a brief sociodemographic survey that asked questions about age, race/ethnicity, income, living situation, government food assistance, nutrition related chronic diseases, and transportation (variables listed in Table 1). Participants were included if they provided informed consent, resided in a rural Montana community, and were 50 years of age or older. The American Association of Retired Persons (AARP) Foundation, funder of this study, defines older adults as 50 years of age or older [27]. Focus group questions were developed by Sharkey [28] and covered several aspects of food choices, including community, food preferences, budgeting, food availability, and food community public programs (Table 2). The semi-structured interview guide corresponds to Story et al. food environment socioecological model, which frames individual consumption patterns as influenced by multiple factors [6]. All interviews were tape-recorded. Focus groups each lasted between 45 and $60 \mathrm{~min}$.

\section{Data Analysis}

Tape-recordings were transcribed verbatim by the research team. Transcriptions were reviewed with tape-recordings by one other researcher to ensure accuracy. Two researchers separately used the constant comparison method to break down transcribed data into meaning units and organize food choices of rural older adults into themes and subthemes framed by the socioecological model at individual, social, and environmental levels [6, 29]. Meaning units that appeared in the transcription more than once were organized as themes and subthemes that emerged from the data. Two additional researchers then reviewed transcription data, meaning units, and themes and subthemes. Four total researchers met, discussed, and agreed upon discrepancies in themes and subthemes.

\section{Results}

\section{Sociodemographic Characteristics of Focus Group Participants}

The sociodemographic results of focus participants are displayed in Table 1. In total, four focus groups were conducted with 33 older adults $(\mathrm{M}=8.25$; range $=4-12)$ living in rural communities in Montana. The four focus groups consisted of $6,7,8$, and 12 participants, were each held at different senior centers, and consisted of mixed gender groups. Participant's mean age was 73.6 (8.8). The majority of participants $(51.5 \%)$ resided in their community for 
Table 1 Sociodemographic characteristics of among older adults in the rural western USA focus group participants

\begin{tabular}{|c|c|c|c|c|c|}
\hline \multicolumn{3}{|c|}{ the rural western USA focus group participants } & \multirow{2}{*}{\multicolumn{2}{|c|}{ Number }} & \multirow[b]{2}{*}{$\%$} \\
\hline & Number & $\%$ & & & \\
\hline \multirow{2}{*}{\multicolumn{3}{|c|}{ Age }} & No & 25 & 75.8 \\
\hline & & & \multicolumn{3}{|l|}{ Transportation } \\
\hline $50-59$ & 2 & 6.1 & Yes & 32 & 97 \\
\hline $60-69$ & 12 & 36.4 & No & 1 & 3 \\
\hline $70-79$ & 10 & 30.3 & \multicolumn{3}{|c|}{ Transportation assistant program participant } \\
\hline $80-89$ & 9 & 27.3 & Yes & 0 & 0 \\
\hline Mean age (+/-SD) & $73.6(8.8)$ & & No & 33 & 100 \\
\hline Education & & & \multicolumn{3}{|c|}{ Miles travelled to purchase groceries } \\
\hline High school & 19 & 57.6 & $0-10$ & 12 & 36.4 \\
\hline College & 14 & 42.4 & $11-20$ & 4 & 12.1 \\
\hline Race/ethnicity & & & $21-30$ & 7 & 21.2 \\
\hline White & 33 & 100 & $31-40$ & 1 & 3 \\
\hline Marital status & 16 & & $41-50$ & 0 & 0 \\
\hline
\end{tabular}

$\begin{array}{lll}\text { Widowed } & 9 & 28.1\end{array}$

$\begin{array}{lll}\text { Divorced/separated } & 6 & 18.8\end{array}$

Single, never married $\quad 1 \quad 3.1$

Resident of current community (years)

$0-10 \quad 3$

$11-20$

21-30 7

$31-40 \quad 1$

$41-50 \quad 8$

51-60 6

$61-70$

$71-80$

Adults in household

1

2

Income

$<10,000$

$10,001-19,999$

20,000-29,999

30,000-39,999

$<40,0000$

Employment

Yes 8

No 18

Supplemental nutrition assistance program (SNAP)

Yes 2

No 31

Diabetes

Yes

No

6

Obesity

Yes

No

31

27

3

30

Heart problems

Yes

Table 1 (continued)

more than 40 years. A large majority (97\%) of participants had transportation available to them that did not include a transportation assistance program $(0 \%)$ and $35.4 \%$ traveled 0-10 miles to purchase groceries.
9.1

6.1

21.2

3

24.2

18.2

3

6.1

45.5

54.5

6.1

18.2

24.3

6

15.1

24.2

54.5

93.9

6.1

18.2

81.8

90.9

9.1

24.2

\section{Themes and Subthemes}

Four themes and 12 corresponding subthemes emerged from focus group data (Table 3). Theme 1, Older Adults' Perceptions of the Rural Community Environment focused on perceived and actual status of infrastructure, transportation, and places to obtain food. Theme 2, Community Support as a means of Increasing Food Access in Rural Places followed the social perspective of the food environment and focused on the importance of neighbors, encouraging use of community resources in social circles, and finding opportunities to eat with others. Themes 3 and 4 were identified as Personal Access to Food Sources for Older Adults in Rural Communities, and Dietary Choices and Consumption Patterns for Older Adults in Rural Communities, respectively. Both themes aligned with the various individual perspectives of the food environment, including personal experience with food affordability, availability, quality, and preferences.

\section{Theme 1: Older Adults' Perceptions of the Rural} Community Environment

Subtheme 1.1: Development of Infrastructure The majority of participants described substantial changes within their communities over time, specifically regarding growth of infrastructure. "I came to [local community] in 1942, so you know I've seen a lot of changes... it was nothing but dirt and gravel 29 years ago," one participant explained. Yet another mentioned, "I got here [local community] in 1974, and I think for probably 10 or 15 years it grew slowly and then it 
started appearing in national magazines as a great place to live and then it took off." All focus group participants noted a significant population increase within their community over time. Many participants were in agreement that the population growth and large development had impacted their communities in a negative way, citing more traffic, higher cost of living, and less friendly atmosphere and were reminiscent of the simpler times. "Times have changed," one participant explained. Some commented on the improved school systems. For example, "I would say we have the best schools, good teachers."

Subtheme 1.2: Availabilityof Transportation Resources The majority of participants were aware if public transportation options existed in their own community. Many participants described public transportation as "not easy to get." Schedules and availability were confusing to some participants, who were asking each other about routes even during the focus group discussions. One participant commented, "I've heard that that bus from [Nearby Community 1] and [Nearby Community 2] will come through [Focus Group Community 1] if there is enough interest. I've heard that, now, I don't know that for a fact." Participants noted that the local senior door to door shuttle service was not as reliable as it had been in the past, only coming "two times a week." Those living in more remote areas lamented the fact that there were no transportation options for them. "It used to be that you could call this [local senior door to door shuttle service] and they would come," according to one participant. Others hoped for expanded services in the future. "They would not even come down for the volunteer programs. It would be nice if we did have a bus, maybe like once a week or you know." The lack of transportation options made shopping for food and other goods in the neighboring larger town a challenge. "I still think though really if we had some sort of transportation, like maybe even once a month, a lot of people could go up there shopping," one participant suggested. Participants living in close-knit communities mentioned that they would often provide transportation for older adults in need to certain events, such as the senior lunches or community gatherings.

Subtheme 1.3: Food Outlets Food sources described by focus group participants included grocery stores, restaurants, discount superstores, and farm to consumer outlets. More rural participants disclosed that there were "no places to get good groceries [in their community]" and "[we have] none [grocery stores], none in our community." Another rural participant responded saying that the only food source available in their community was "just a convenience store on the hill up there...that's all." Thus, many rural participants either have to make do with the local convenience store or drive to a larger city in order to purchase their groceries. Many of the participants agreed, "You have to go to [a larger town to get groceries]." "We usually drive to [the town nearby] about once every 2 weeks," one participant explained. However, a few noted that they would not actually go out of their way to drive to the nearby town just to get groceries, but would "pick up some stuff" if they were already there. A few participants mentioned that they frequented Costco for their food buying in bulk, "We love Costco."

Subtheme 1.4: Food Bank and Food Pantries Participants were overwhelmingly in agreement that the local food bank and pantries were the most prevalent and widely used community food programs in the area. Food banks and pantries both directly distributed food locally to individuals and were set up in a supermarket style to give clients choices. One participant described that the food bank and pantries provided "probably the major source of food." Participants showed strong support and enthusiasm for the food bank and pantries, particularly the willingness of those running the food banks to accommodate the needs of the older adults, as well as quality of the food selection. Autonomy and flexibility were important to older adults when choosing to use the food banks' resources. One participant used the food bank as a means of acquiring ingredients for cooking, a passion of hers: "The [local food bank] delivers to me and we get a lot of rice and beans. I like the way they send me dried things so I can cook like I want to because I do all my own cooking." Some participants were on a first-name basis with the managers of the food bank and pantries, and appreciated their attention to individual needs. "Well, you know, I went to the [local food pantry] and they had all these apples, and nobody was taking them," said one participant, "and so I talked to [the food bank director] and I said, 'You know, I'd like to make apple butter and applesauce,' and she gave me apples and they delivered them to my house."

The food bank and pantries were also noted for their high-quality foods, bolstered by the communities that support them. Explained one participant, who frequented the food banks often, "[What] I really love about the [local food bank] is when local farmers give us their produce. I am so psyched every time I get an organic tomato because I don't have the income coming in for these things. And, so, I bless the community of [focus group community] because they're really a conscious group of people... The government senior foods...I give it away to all the people who still eat that kind of stuff, but I couldn't eat past that block of cheese, that'll clog me up." Other participants commented adversely about the "sweets" available at the food bank and pantries, "I would really like to see our quality change for the elderly ... an improvement in the quality of food that is provided at the food bank. In the cooler there are cakes and pies because people aren't eating them anymore, so we are getting them." 
Table 2 Focus group interview question topics for factors influencing food choices among older adults in the rural western USA

Description of community

Community food sources

Food decision making at point of purchase

Food resources for food insecure

Social opportunities for food acquisition

Personal food choices and eating patterns

Community food security

Suggested changes in community eating habits and food resources

Open discussion

Participants also shared approval of the food bank and pantries' adjunct programs, including a program serving free meals in a restaurant-like setting, programs providing food for children to take home after school as well as summer lunches, and an on-site garden. "[The programs] really have increased in numbers," stated one participant.

Subtheme 1.5: Community Food Program Participation Some participants cited that participation in community food programs was dependent on availability of food programs, knowledge of their existence, and admitting need for assistance. For example, one participant mentioned, "We need more participation like Meals on Wheels, [which] we don't have. We have a lot of people who don't...they won't call for the service even though they qualify. I don't know why. Maybe they don't know about it or maybe they don't...got too much pride or something?" Another participant responded saying, "I think there's a lot of people who don't want to admit they need stuff."

Participants also noted other community food programs for older adults, both those organized by local communities as well as government assistance programs, such as "coupons for farmers' markets." Senior center meals were popular due to the nutritional quality of the meals. "I love the meals here [at the local senior center]," expressed one participant, "I have no complaints because they serve me vegetables and fruits and meat...I think they have a dietitian here. Yes, I'm sure they do." Another participant described participation and volunteer turnout for the dinner program conducted by the local food bank as "amazing." Churches also served as food resources for older adults, both as a place to acquire food, such as "potlucks," and a place to help those in need. These community outreach efforts included "a collection of food the first Sunday of every month [that's] taken to the [local food bank]."

\section{Subtheme 1.6: Self-Sufficient Methods of Obtaining} Food Although many older adults reported relying on more conventional ways of obtaining food, such as grocery stores or food assistance programs, some relied on more self-sufficient methods of acquiring their food. A numerous
Table 3 Themes and subthemes for factors influencing food choices among older adults in the rural western USA

\begin{tabular}{|c|c|}
\hline Number & Theme and subthemes \\
\hline 1 & $\begin{array}{l}\text { Older adults' perceptions of the rural com- } \\
\text { munity environment }\end{array}$ \\
\hline 1.1 & Development of infrastructure \\
\hline 1.2 & Availability of transportation resources \\
\hline 1.3 & Food outlets \\
\hline 1.4 & Food bank and food pantries \\
\hline 1.5 & Community food program participation \\
\hline 1.6 & Self-sufficient methods of obtaining food \\
\hline 2 & $\begin{array}{l}\text { Community support as a means of increasing } \\
\text { food access in rural places }\end{array}$ \\
\hline 2.1 & Neighbors as a safety net \\
\hline 2.2 & $\begin{array}{l}\text { Strategies to encourage use of the commu- } \\
\text { nity food system }\end{array}$ \\
\hline 2.3 & Opportunities to eat in the company of others \\
\hline 3 & $\begin{array}{l}\text { Personal access to food sources for older } \\
\text { adults in rural settings }\end{array}$ \\
\hline 3.1 & $\begin{array}{l}\text { Fruits and vegetables availability, quality, } \\
\text { and affordability }\end{array}$ \\
\hline 3.2 & Affordability of food \\
\hline 4 & $\begin{array}{l}\text { Dietary factors affecting food choices and } \\
\text { consumption patterns }\end{array}$ \\
\hline 4.1 & Dietary choices and restrictions \\
\hline 4.2 & Food patterns \\
\hline 4.3 & Traditional influences \\
\hline
\end{tabular}

amount of the focus group participants reported that they have had a garden or take part in some type of community garden. One rural participant explained that, "Life in my community is a little bit different. I have a greenhouse and I can grow a salad and keep myself eating salad all summer through fall." Another participant proclaimed, "Gardens? Oh yeah, we [used] to have a huge garden [because] we had five children. Here [where I currently reside] we just have little ones around our house [with] fresh veggies...you know tomatoes, lettuce, peas, and beans." One participant mentioned that they "raise tomatoes here at the [local] senior center, flowers and tomatoes." Another participant commended the food bank for promoting recipes and for giving out plants for people to grow in at their own homes. They stated, "If we were encouraged and given small means to grow food in our yards and in our windows, that could be a huge thing."

Although the majority of participants communicated that while they had a garden at least at one point in their lives, as they continue to age, it has become increasing difficult to keep up with the physical demands of gardening, especially with the Montana climate. Thus, a few stated they no longer have their own garden, but visit the farmer's market instead or are given some produce from other members of 
the community. "Not much grows in the winter unless you have a greenhouse or something," one participant explained.

Focus group participants also mentioned foraging as another self-sufficient means to acquiring food. One stated, "I love foraging foods. I do stinging nettles a lot" and another proclaimed, "We need to have a grazing club for ladies!" A few participants mentioned cooking, canning, and fermenting foods as well. Other participants mentioned utilizing cherry and apple trees that were plentiful in their communities in order to make pies or jams. Another said "I like apples...there's apple trees here and you can pick them up and they're just fine [to eat]."

\section{Theme 2: Community Support As a Means of Increasing Food Access in Rural Places}

Subtheme 2.1: Neighbors as a Safety Net While older adults often avoided community programs due to social stigmas of relying on food assistance or appearing elderly or unable to care for themselves, many participants revealed that they and their neighbors provided social support for one another on a more personal, one-on-one level. Much of this support occurred by the sharing of food in a home setting, "I do a tremendous amount of cooking. I'm still cooking for seven," said one participant, "I [make] a big pot of [stew] and so my neighbors get it or whatever...I enjoy cooking." These interactions were very important to them, saying that they enjoyed their living situations because they "manage to care for one another... and there's more sociability...there's more friendliness and caretaking." This sort of sharing, with neighbors looking out for one another, was common.

Sharing one's food was also a way to fill larger social needs in the community. For example, "I had an abusive husband and one way he did it was I didn't get to eat, and the neighbors, I would babysit their children and take care of them and teach them literacy and she would make sure I got food." One participant explained her relationship with her neighbors: "There's a guy next door, and I bring him hot soup. He'll come over and ask for it, and I'll give him some bread. We call it 'hunt and gather,' to give it more dignity."

Subtheme 2.2: Strategies to Encourage Use of the Community Food System Social groups supported each other with encouragement to utilize food assistance programs "I've told a number of people about the Food Bank and [emergency dinner restaurant]," shared one participant. The key to providing social support through food assistance seemed to be presenting the help as a sign of friendship and neighborliness, not charity, as one participant explained, "When I get something from the Food Bank, my neighbors will eat that stuff, so I tell them, 'This isn't really a favor, but you can eat this if you want,' and they do." Another participant stated that, "The food that I don't eat I share with my neighbors because they're literally starving and a lot of them are in wheelchairs. They'll eat just about anything so it's better than nothing. I'm just grateful that I can share."

Subtheme 2.3: Opportunities to Eat in the Company of Others While one-on-one interactions and connections drove most social relationships and sharing of food resources, many participants expressed a desire for more opportunities for socializing and support. Most older adults ate alone, "unless I come to the [local senior center]." One participant stated, "I'd love to eat with more people. I've gotten isolated." Support for peers was strong throughout the groups, and many discussed wanting to reach out to others and help older adults who were in need or resources, or just lonely. "I think there's a lot of people who don't want to admit they need stuff, and it's too bad, because those are the people we're trying to help."

According to participants, the senior center provided a casual opportunity for older adults of all ages to socialize and share a meal together. One barrier to attending the senior center was stated in many ways, "They consider it, oh, the senior center, that's just all old people." Others cited pride as a factor in keeping people away from the senior center and other community programs, "It's, I think, it's really called pride. A lot of people think this is a welfare thing in here....and only people that are destitute show up."

\section{Theme 3: Personal Access to Food Sources for Older Adults in Rural Settings}

Subtheme 3.1: Fruits and Vegetables Availability, Quality, and Affordability Focus group participants spoke about their personal level of fruit and vegetable consumption being mainly influenced by availability, quality, and affordability. Where participants spoke of purchasing and consuming produce, food quality influenced their overall desire to consume fruits and vegetables. "A lot of people garden. I personally use grocery stores, or farmer's market," one participant declared. Although many of the participants mentioned that they do purchase fresh produce in grocery stores, it was a challenge to find quality produce. "Produce is the toughest for groceries," one participant declared. Another participant stated, "Yeah they don't have as big a turn-over of rotting food down here because limited people and supply you know." Price was intertwined with the conversation about food quality and was extremely influential on senior's consumption of fresh produce. One participant stated, "It's hard to keep fruit, because either you don't have enough or it goes bad on ya....and the fruit is so expensive over at the store."

Farm to consumer outlets were discussed as a high quality and affordable food option for many focus group 
participants, "Well, in the summertime we do a farmer's market...set it up at the local grocery store once a week. So anybody that has their vegetables can bring all their stuff to the farmer's market." Other participants mentioned a mobile farmers market that came to their community. "Well last summer there was a food truck that came and delivered food about once every Tuesday I think it was." Other fruit and vegetable resources were mentioned, "You can get a beautiful, I forget what they're called...for $\$ 15 \ldots$ and you get more [fruits and vegetables] than you can think about eating." "Bountiful, those bountiful baskets," another participant explained.

Subtheme 3.2: Affordability of Food For older adults, cost was the largest barriers to food access due to a fixed income. "I live on $\$ 917$ [a month] ...I didn't get a big social security," one participated stated. The majority of participants were in agreement that "price" was the determining factor in deciding what foods they ultimately buy. One participant mentioned that, "Nobody's starving around here, but there's some people are struggling finance wise and they don't...I mean they can't even afford to come up here [local senior center] to eat."

Many of the focus group participants shared methods of making their food dollars stretch, including looking for sales at their local grocery stores and buying cheaper, less attractive produce to save money. One participant stated, "I'm generally watching for sales on fruits and vegetables, [I buy] the 99 cent apples rather than the $\$ 2$ per pound apples." The majority of participants mentioned that produce was the most expensive food item to buy. "If people have a limited income, fruit is expensive." Others spoke about buying specific food items in order to make them last. "If you can dodge spending money on expensive foods, you can get a big chunk of [salmon] for 99 cents." One participant suggested, "I can get two or three meals out of it. I can do that with the rice, then I can put in some scrubbed up greens or whatever's cheap in the greens department and eat that all day long." Another participant mentioned "she could make potato soup in fifteen minutes, usually with any ingredients left over in the house if finances were tight."

\section{Theme 4: Dietary Factors Affecting Food Choices and Consumption Patterns for Older Adults in Rural Settings}

Subtheme 4.1: Dietary Choices and Restrictions Participants demonstrated that they made food choices based on what they perceived as "healthy", although the idea of "healthy" foods varied greatly. "Instead of using butter," suggested one participant, "I'll use coconut oil or something like that, or I'll use gluten-free substitutes." Participants from more rural communities tended to view health food differently, emphasizing whole, hearty, homemade foods, such as "soup with stuff off the shelves." Participants were also aware of making healthy choices such as switching brown rice for white rice, or whole grain bread for white bread.

While most had an understanding of health and nutrition issues, others were still confused about making healthy choices. "I don't know what you're supposed to eat," stated one participant. Another participant was particularly confused by public dietary guidance, noting that "...the government says 'Don't eat eggs, they're bad for you.' Then they come out and they say eggs are good for you."

Information used to make these food choices came from a wide range of sources. Many participants stated that their doctor recommended consumption of more fruits and vegetables and less sugar. One participant explained, "Well I have an excellent doctor... and he wanted me to buy some pills and I said, 'Well, I really can't... and they gave me a list of various things that I require, and I follow and I don't buy the meds...It's a little more pricey, yes, but I feel safer taking and eating vegetables and fruits than taking meds." When discussing healthy eating choices, however, most participants recited information they had heard from an unspecified source, including from "the internet." Others acquired nutrition information themselves by reading nutrition labels and being aware of ingredients in their foods.

Many participants also had dietary restrictions and health concerns that dictated their food choices. Participants reported avoiding milk, refined wheat, chemicals, MSG, and sugar. Several participants avoided excessive consumption of sugar in an effort to manage their diabetes and other health issues, stating, "sugar causes cancer, too."

Subtheme 4.2: Food Preferences Food preferences varied greatly among participants, although most enjoyed staple foods and starches. "We always have spaghetti on hand and some macaroni," said one participant, a statement echoed by several others who consumed pastas regularly. Potatoes, rice, and bread were all commonly consumed foods, with several participants noting a preference for a "meat and potatoes" diet. Still, others preferred fruits and vegetables, specifically cantaloupe and apples. Participants generally preferred unprocessed foods over processed foods, with one participant even insisting on "no frozen dinners."

Subtheme 4.3: Traditional Influences Foods eaten during childhood or food patterns resembling those of past generations were popular among participants. Many sought to emulate the way their parents or great-grandparents ate, and dismissed current health trends or recommendations. "My dad ate two eggs a day for years no problem," stated one participant. Another participant pointing out that, "Dad lived to be 90 years old and lived on the farm all his life and ate bacon and butter and cream." An increased focus on balance of calorie intake and calorie output was also a 
concern of many participants, "I kind of go along with what my grandfather always said, 'It's not so much what you eat, it's how much." Physical activity was also mentioned, "My grandparents, great-grandparents, they ate all that stuff that was not good for you cooked in pork fat....and a lot of them lived to be 90 years old... and they worked outside in the sun. They worked a lot harder than anybody does now."

Participants also tended to have fond memories of foods they ate while growing up, noting the importance of their heritage in their food choices. One participant shared that her food choices were influenced by her childhood growing up on a farm during the Great Depression: "We ate wild plums and that was our fruit. And my mother would bake bread, of course, everybody did then... and we ate chokecherries for fruit, chokecherry juice for juice, chokecherry jam or jelly."

\section{Discussion}

When developing strategies, programs, and interventions to promote healthy nutrition among older adults in rural communities of the western USA, it is important to first gather information from older adults about the opportunities and challenges they face when making food choices. The findings from this focus group study suggest that several factors influence food choices of older adults in rural communities of the western USA. Four major themes related to factors influencing food choices among rural older adults in the western USA emerged from this study: perception of the rural community environment, community support, personal food access, and dietary factors influencing food consumption. Findings spanned the food environment socioecological framework provided by Story et al., including individual, social, environmental factors [6].

On the individual level, participants reported that the greatest barrier to food choices for older adults in their rural communities was cost and food quality, especially in relationship to produce. Some participants stated that they lived on a fixed income and had limited capacity to purchase food. Food purchases were based on cost and participants shared methods to make food dollars stretch. Limited financial resources altered food choices and quality, which ultimately affects health outcomes of older adults [30-32]. The discussion about produce quality is in line with findings from Byker et al. that fruits and vegetables in rural environments are lower in quality than in urban environments [33]. Additionally, older adults indicated that buying produce was frustrating, as often the produce would go bad before they could consume the expensive food product. Many participants counteracted this lack of grocery store produce by utilizing local farm-to-consumer outlets.
Participants stated specific dietary factors that contributed to their food choices, including dietary choices and restrictions, food preferences, and traditional influences. Most participants reported making food choices based upon what they perceived as healthy, although the definition varied. Most participants indicated that a diet low in sugar and high in fruit and vegetables was healthy. Many reported other prevalent nutritional myths. Even so, many participants were confused by which food choices were healthy with recommendations constantly changing. A study by Thomas and colleagues found that older adults had nutrition knowledge but were not clear about how to apply it [34]. Participants also claimed to gain nutritional knowledge from the Internet or their care provider for nutritional information. Research reports that nutrition information on the Internet is accurate or inaccurate to varying degrees [35] and that seniors feel they receive insufficient nutrition counseling form their health care provider [36]. Food preferences varied greatly among participants. Interestingly, traditional foods eaten during childhood were favored among participants. Many participants discussed their parents' and grandparents" "unhealthy" food patterns in relationship to their long years of life, noting their positive health status during later years of their life despite a diet that contradicted conventional dietary recommendations.

On the social level, participants indicated that food choices were increased through social support of communities. Interestingly, participants did not indicate whether or not they were willing to take food from their neighbors; they only discussed sharing with others. The concept of food sharing is not completely uncommon among older adults [37]. The results from one study about food sharing indicated that $75 \%$ of the older adults in the study reported receiving a food gift during the year [38]. Participants reported that sharing mealtimes was a potential strategy to decrease social isolation. Holmes and Roberts reports that social interaction at mealtimes is related to increased dietary quality [39].

On the environmental level, participants indicated that the community environment had experienced significant changes in infrastructure development and variable availability of transportation over time. Older adults reported significant development in their rural communities, although public transportation was unreliable, unavailable, or, if transportation was available, they had difficulty understanding the schedule. While the majority of participating older adults had a reliable form of non-public transportation, these factors may have contributed to this lack of use of public transportation systems in their rural communities. Development in their communities did not include food outlets or options, but rather buildings, roads, and population growth. Public transportation issues are prevalent in rural areas and are a defining factor in rural food deserts [40]. Public 
transportation may be particularly important for older adults to access foods in rural areas with long distances between food outlets and little physical mobility [32, 41].

While all participants indicated that they utilized local grocery stores and some utilized community food sources to secure food items, many noted that they also produced their own food through gardens. Participants reported utilizing traditional gardens and community gardens, or downsizing or ending the garden due to the physical inability. Many participants also discussed foraging and canning, freezing, and fermenting food as a way to supply food sources throughout the year. Quandt and colleagues also found that Kentucky elderly populations practiced gardening and food preservation techniques in large part due to their rural background and family traditions [42].

Also at the environmental level, many participants stated that they were aware of several community food sources that were available to older adults in the community, including food bank and pantries and additional community food programs. Participants, however, admitted that these services were not well utilized. The food bank and pantries were noted as the most frequented community food resource. In this study, participants felt that the food bank and pantries offered flexibility and autonomy in services. This concept is supported by findings from a United Kingdom study of elderly individuals that reported not using services available to them or terminating these services due to inflexibility of services [43]. Among other community food sources, including community dinners, senior center meals, and government assistance, the participants indicated that low participation might be due to a lack of knowledge, as well as social stigma of being identified as old or poor. Other studies have found that older adults more likely to participate in food assistance also demonstrate help-seeking behavior $[44,45]$. Many participants commented specifically that the senior centers, which have evolved to fill nutritional, social, and physical assistance needs, were seen for the old and poor. Further research should focus on better understanding what constraints and opportunities exist for increased social service utilization in rural elderly populations.

A diversity of community and personal food sources were reported to meet the food needs to varying degrees for older adults in these rural communities that were influenced by all levels of the socioecological model. Food sources included traditional food outlets, area food bank and pantries, community food programs, self-sufficient methods, and social networks. For many of the participants, local grocery stores were not available to them; they utilized smaller food outlets in town and had to travel to larger towns for grocery stores. Powell and colleagues also found that convenience stores are more likely to exist in rural areas than chain supermarkets [46]. In addition, other research has found that smaller food outlets are more likely to have increased energy-dense and processed foods [12] and that dietary choices are influenced by food store availability [47].

Themes, subthemes, and meaning units emerged from the rural western USA data that are also found in research with older adults across the United States. In particular, the idea throughout our findings surrounding stigma for assistance is a prevailing concept in older adult populations [44, 45]. Social isolation that impacts well-being is a dominant issue among older adult populations [7, 20]. Further research should confirm why other topics prevalent in older adult nutrition research did or did not emerge in this rural western USA population.

Limitations exist in this study. Study participants included a small, convenience sample of older adults. Participants in this study were drawn from senior centers, which may not reflect the findings from research with older adults who do not attend senior centers. Findings may not apply to larger populations of older adults. Information shared from older adults might not reflect that of a larger older adult population, as participation was voluntary. Study findings were not validated with actual food choice patterns of older adults.

\section{Conclusions}

Increasing the availability and access to nutritious and affordable food choices should play a role in planning for strategies, programs, and interventions that target nutritional needs of older adults in rural areas in the western USA and around the USA. The findings from this study warrant further research and specifically tailored approaches that influence the food choices of older adults in the rural western USA, including the development of public transportation, expansion of local grocers with quality and affordable food options, increasing awareness and decreasing stigma surrounding community food programs, and increasing nutrition education targeting senior health issues. Many of these efforts require policy and environmental changes to improve the food environment [6]. Although older adult food needs overlap with the food needs of other health disparate populations and rural food deserts, care should be taken to respect the nuances in population preferences towards food choices [48]. For example, providing community gardens that are both tailored towards the physically compromised and growing traditional fruits and vegetables may increase utilization by older adults.

By 2040, the older adult population (65 years of age and older) is expected to grow to 82.3 million in the United States, nearly doubling the population size from the year 2000 [49]. Important to note, a large majority of the current rural population consists of older adults [50] and many older adults choose to migrate to rural areas in retirement years $[51,52]$. With the age of the baby boomer generation 
rapidly increasing, developing methods to increase healthy food choices now will promote health and quality of life among the growing older adult population in rural areas for years to come.

Acknowledgments The authors would like to thank the AARP Foundation for financially supporting the work completed in this study through their Hunger Innovation Grants. AARP Foundation is working to win back opportunity for struggling Americans $50+$ by being a force for change on the most serious issues they face today: housing, hunger, income and isolation.

\section{Compliance with Ethical Standards}

Conflict of Interest The authors declare that they have no conflict of interest.

\section{References}

1. Ory, M. G., \& Cox, D. M. (1994). Forging ahead: Linking health and behavior to improve quality of life in older people. Social Indicators Research, 33(1-3), 89-120.

2. Drewnowski, A., \& Evans, W. J. (2001). Nutrition, physical activity, and quality of life in older adults: Summary. The journals of Gerontology. Series A, Biological Sciences and Medical Sciences, 56(Suppl 2), S89-S94.

3. Amarantos, E., Martinez, A., \& Dwyer, J. (2001). Nutrition and quality of life in older adults. The Journals of Gerontology. Series A, Biological Sciences and Medical Sciences, 56(Suppl 2), S54-S64.

4. Kerschner, H., \& Pegues, J. A. (1998). Productive aging: A quality of life agenda. Journal of the American Dietetic Association, 98(12), 1445-1448.

5. Stokols, D. (1996). Translating social ecological theory into guidelines for community health promotion. American Journal of Health Promotion: AJHP, 10(4), 282-298.

6. Story, M., Kaphingst, K. M., Robinson-O'Brien, R., \& Glanz, R. (2008). Creating healthy food eating environments: Policy and environmental approaches. Annual Review of Public Health, 29, 253-272. doi:10.1146/annurev.publhealth.29.020907.090926.

7. Dean, W. R., Sharkey, J. R., \& Johnson, C. M. (2011). Food insecurity is associated with social capital, perceived personal disparity, and partnership status among older and senior adults in a largely rural area of central Texas. Journal of Nutrition in Gerontology and Geriatrics, 30(2), 169-186.

8. Lee, J. S., Frongillo, Jr., E. A. (2001). Nutritional and health consequences are associated with food insecurity among U.S. elderly persons. The Journal of Nutrition, 131(5), 1503-1509.

9. Frongillo, E. A., \& Horan, C. M. (2004). Hunger and aging. Generations, 28(3), 28-33.

10. Sharkey, J. R. (2011). Food security in older adults. Journal of Nutrition in Gerontology and Geriatrics, 30(2), 103-104.

11. Caspi, C. E., Sorensen, G., Subramanian, S. V., \& Kawachi, I. (2012). The local food environment and diet: A systematic review. Health \& Place, 18(5), 1172-1187.

12. Morton, L. W., \& Blanchard, T. C. (2007). Starved for access: life in rural America's food deserts. Rural Realities, 1, 1-10.

13. Liese, A. D., Weis, K. E., Pluto, D., Smith, E., \& Lawson, A. (2007). Food store types, availability, and cost of foods in a rural environment. Journal of the American Dietetic Association, 107(11), 1916-1923.

14. Krukowski, R. A., West, D. S., Harvey-Berino, J., \& Prewitt, T. E. (2010). Neighborhood impact on healthy food availability and pricing in food stores. Journal of Community Health, 35(3), 315-320.

15. Lutfiyya, M. N., Chang, L. F., \& Lipsky, M. S. (2012). A crosssectional study of US rural adults' consumption of fruits and vegetables: Do they consume at least five servings daily? $B M C$ Public Health, 12, 280.

16. Befort, C. A., Nazir, N., \& Perri, M. G. (2012). Prevalence of obesity among adults from rural and urban areas of the United States: Findings from NHANES (2005-2008). The Journal of Rural Health: Official Journal of the American Rural Health Association and the National Rural Health Care Association, 28(4), 392-397.

17. Tai-Seale, T., \& Chandler, C. (2010). Nutrition and overweight concerns in rural areas: A literature review. In Rural Healthy People 2010: A Companion Document to Healthy People 2010 (Vol. 2). College Station, TX: Southwest Rural Health Research Center, School of Rural Public Health.

18. Quandt, S. A., \& Rao, P. (1995). Hunger and food security among older adults in a rural community. Human Organization, 58(1), 28-35.

19. Quandt, S. A., McDonald, J., Arcury, T. A., Bell, R. A., \& Vitolins, M. Z. (2000). Nutritional self-management of elderly widows in rural communities. The Gerontologist, 40(1), 86-96.

20. Quandt, S. A., Arcury, T. A., Bell, R. A., McDonald, J., \& Vitolins, M. Z. (2001). The social and nutritional meaning of food sharing among rural adults. Journal of Aging Studies, 15(2), 145-162.

21. Vitolins, M. X., Tooza, J. A., Golden, S. L., Arcury, T. A., Bell, R. A., Davis, C., Devellis, R. F., \& Quandt, S. A. (2007). Older adults in the rural south are not meeting healthful eating guidelines. Journal of the American Dietetic Association, 107(2), $265-272$.

22. Ledikwe, J. H., Smiciklas, W. H., Mitchell, D. C., Miller, C. K., \& Jensen, G. L. (2004). Dietary patterns of rural older adults are associated with weight and nutritional status. Journal of the American Geriatrics Society, 52(4), 589-595.

23. Champagne, C. M., Casey, P. H., Connell, C. L., Stuff, J. E., Gossett, J. M., Harsha, D. W., McCabe-Sellers, B., et al. (2007). Poverty and food intake in rural America: Diet quality is lower in food insecure adults in the Mississippi Delta. Journal of the American Dietetic Association, 107(11), 1886-1894.

24. Souter, S., \& Keller, C. S. (2002). Food choice in the rural dwelling older adult. Southern Online Journal of Nursing Research, $5(3), 1-19$.

25. Ledikwe J. H., Smiciklas W. H., Mitchell D. C., Miller C. K., Jensen G. L., Friedmann J. M., Still C. D. (2007). Nutritional risk assessment and obesity in rural older adults: A sex difference. The American Journal of Clinical Nutrition, 77(3), 551-558.

26. USDA Economic Research Service (2013). Rural-Urban Continuum Codes. Accessed Sept 10, 2016, from http://www.ers.usda. gov/data-products/rural-urban-continuum-codes.

27. AARP.org. (2016). AARP Foundation. Accessed Sept 10, 2016, from http://www.aarpfoundation.org/.

28. Sharkey, J. (2012). Rural food choices focus group guide.

29. Glaser, B. G., \& Strauss, A. L. (1967). The discovery of grounded theory: Strategies for qualitative research (7th edn.). Chicago, IL: Aldine Publishing Company.

30. Keller, H. H., \& Dywer J. J. M. (2007). A social ecological perspective of the influential factors for food access described by low-income seniors. Journal of Hunger \& Environmental Nutrition, 1(3), 27-44. doi:10.1300/J477v01n03 03.

31. Sharpe, D. L., Huston, S. J., \& Finke, M. S. (2003). Factors affecting nutritional adequacy among single elderly women. Family Economics and Nutrition Review, 15(1), 74.

32. Dean, M., Raats, M. M., Grunert, K. G., \& Lumbers, M. (2009). Factors influencing eating a varied diet in old age. Public Health Nutrition, 12(12), 242-247. doi:10.1017/S1368980009005448. 
33. Byker Shanks, C., Ahmed, S., Smith, T., Houghtaling, B., Jenkins, M., Margetts, M., Schultz, D., \& Stephens, L. (2015). Availability, price, and quality of fruits and vegetables in 12 rural montana counties. Preventing Chronic Disease, 12, 150-158.

34. Thomas, L., Almanza, B., \& Ghiselli, R. (2010). Nutrition knowledge of rural older populations: Can congregate meal site participants manage their own diets? Journal of Nutrition for the Elderly, 29(3), 325-344. doi:10.1080/01639366.2010.500951.

35. Ostry A., Young M. L., Hughes M. (2008). The quality of nutritional information available on popular websites: A content analysis. Health Education Research, 23(4), 648-655. doi:10.1093/ her/cym050. (Epub Sept 25 2007).

36. Shatenstein, B. (2008). Impact of health conditions on food intakes among older adults. Journal of Nutrition for the Elderly, 27(3-4), 333-361.

37. Vesnaver, E., \& Keller, H. H. (2011). Social influences and eating behavior in later life: A review. Journal of Nutrition in Gerontology and Geriatrics, 30(1), 2-23. doi:10.1080/01639366.2011.545 038 .

38. Quandt, S. A., Arcury, T. A., McDonald, J., Bell, R. A., \& Vitolins, M. Z. (2001). Meaning and management of food security among rural elders. $J$ Appl Gerontol, 20(3), 356-376. doi: $10.1177 / 073346480102000307$.

39. Holmes, B. A., \& Roberts, C. L. (2011). Diet quality and the influence of social and physical factors on food consumption and nutrient intake in materially deprived older people. European Journal of Clinical Nutrition, 65(4), 538-545. doi:10.1038/ ejcn.2010.293 (PubMed PMID: 21266981).

40. Dean, W. R., \& Sharkey, J. R. (2011). Rural and urban differences in the associations between characteristics of the community food environment and fruit and vegetable intake. Journal of Nutrition Education and Behavior, 42(6), 426-433.

41. Ver Ploeg M., Breneman V., Farrigan T., et al. (2009). USDA economic research service. Access to Affordable and Nutritious Food: Report to Congress. Accessed Sept 10, 2016, from http:// www.ers.usda.gov/publications/ap/ap036.
42. Quandt, S. A., Popyach, J. B., \& DeWalt, K. M. (1994). Home gardening and food preservation practices of the elderly in rural Kentucky. Ecology of Food and Nutrition, 31(3-4), 183-199. doi :10.1080/03670244.1994.9991360.

43. Themissi-Huber, M., Huber, M., \& Munro, P. (2007). Frail older people's experiences and use of health and social care services. Journal of Nursing Management, 15(2), 222-229.

44. Haider, S. J., Jacknowitz, A., \& Schoeni, R. F. (2003). Food stamps and the elderly: Why is participation so low? The Journal of Human Resources, 38, 1080-1111.

45. Kirang, K., \& Frongilla, E. A. (2009). Patterns of food insecurity and participation in food assistance programmes over time in the elderly. Public Health Nutrition, 12(11), 2113-2119.

46. Powell, L. M., Slater, S., Mirtcheva, D., Bao, Y., \& Chaloupka, F. J. (2007). Food store availability and neighbored characteristics in the United States. Preventive Medicine, 44(3), 189-195.

47. Morland, K., Wing, S., Roux, A. D., \& Poole, C. (2002). Neighborhood characteristics associated with the location of food stores and food service places. American Journal of Preventive Medicine, 22(1), 23-29.

48. Duerr, L. (2003). Assessing nutrition education wants and needs of older adults through focus groups. Journal of Nutrition for the Elderly, 23(2), 77-91. doi:10.1300/J052v23n02 06.

49. US Department of Health and Human Services Administration of Aging. (2016). Future Growth. Accessed Sept 10, 2016, from http://www.aoa.acl.gov/Aging_Statistics/index.aspx. .

50. US Department of Health and Human Services (2008). The 2008 report to the secretary: Rural health and human services issues. Rockville, MD: U.S. Government Printing Office.

51. Plane, D. A., Henrie, C. J., \& Perry, M. J. (2005). Migration up and down the urban hierarchy and across the life course. Proceedings of the National Academy of Sciences, 102(43), 15313-15318. doi:10.1073/pnas.0507312102.

52. Cromartie, J., \& Nelson, P. (2009). USDA economic research service. Baby boom migration and its impact on rural America. Washington, D.C.: U.S. Government Printing Office. 